\title{
Hubungan Karakteristik dan Pengetahuan Orang Tua tentang Cara Pemeliharaan Kesehatan Gigi dengan Kejadian Lubang Gigi pada Balita di Posyandu Jeruk Kelurahan Pondok Labu Jakarta Selatan
}

\author{
Ngatemi, S.Si.T, MKM ${ }^{1}$, Emini, S.Si.T, M.A.Kes ${ }^{1}$, Nur Afni ${ }^{1}$ \\ ${ }^{1}$ Jurusan Keperawatan Gigi Poltekkes Kemenkes Jakarta I \\ Email: ngatemi02@yahoo.com
}

\begin{abstract}
Abstrak
Kesehatan Gigi dan Mulut anak di Indonesia masih sangat memprihatinkan sehingga perlu mendapatkan perhatian yang serius dari tenaga kesehatan. Masalah utama yang terjadi dalam rongga mulut adalah karies gigi. PDGI (Persatuan Dokter Gigi Indonesia) menyebutkan bahwa sedikitnya $89 \%$ penderita karies adalah anak-anak. Berdasarkan hasil karakteristik survei kesehatan, prevalensi karies gigi pada balita usia 3-5 tahun sebesar $81,7 \%$. Penelitian ini bertujuan untuk mengetahui hubungan karakteristik dan pengetahuan ibu tentang tata cara pemeliharaan kesehatan gigi dengan kejadian lubang gigi pada balita di Posyandu Jeruk Kelurahan Pondok Labu Jakarta Selatan tahun 2018. Penelitian ini merupakan penelitian deskriptif dengan desain cross sectional. Sampel penelitian menggunakan total sampling berjumlah 47 orang ibu balita umur 4-5 tahun yang datang ke Posyandu Jeruk Pengumpulan data melalui kuesioner dan observasi lubang gigi oleh petugas. Analisis data dilakukan secara univariat, bivariat, dan multivariat. Hasil analisis univariat menunjukkan kejadian lubang gigi sebagian besar dalam kategori tinggi $(57,4 \%)$, umur ibu $<32$ tahun $(66,6 \%)$, pendidikan ibu tinggi $(66,0 \%)$, dan pengetahuan sebagian besar tinggi $(63,8 \%)$. Hasil analisis bivariat, variabel yang berhubungan secara bermakna dengan kejadian lubang gigi adalah pendidikan $(\mathrm{p}=$ $0,007$ dan $\mathrm{OR}=9,692)$, dan pengetahuan $(\mathrm{p}$ $=0,004$ dan $\mathrm{OR}=11,250)$. Sedangkan yang tidak bermakna adalah umur $(\mathrm{p}=0,667)$. Hasil analisis multivariat, variabel yang dominan berhubungan dengan kejadian lubang gigi pada balita adalah pengetahuan ibu $(\mathrm{OR}=9,068)$.
\end{abstract}

Kata kunci: Lubang gigi, karakteristik, pengetahuan ibu

\begin{abstract}
Child's Dental and Oral Health in Indonesia is still very alarming so it needs serious attention from health workers. The main problem that occurs in the oral cavity is dental caries. PDGI (Indonesian Dentist Association) states that at least $89 \%$ of caries sufferers are children. Based on the results of the characteristics of the health survey, the prevalence of dental caries in 3-5 year olds is $81.7 \%$. This study aims to determine the relationship between the characteristics and knowledge of mothers about dental hygiene procedures with the incidence of tooth holes in infants in Posyandu Jeruk, Pondok Labu Village, South Jakarta in 2018. This study was a descriptive study with a cross sectional design. The research sample used total sampling totaling 47 mothers of children aged 4-5 years who came to the Posyandu Jeruk. Data collection through questionnaires and observation of tooth holes by officers. Data analysis was conducted in univariate, bivariate, and multivariate. The results of univariate analysis showed that the incidence of tooth decay was mostly in the high category $(57.4 \%)$, mother age $<32$ years $(66.6 \%)$, high maternal education $(66.0 \%)$, and knowledge was mostly high $(63.8 \%)$. The results of the bivariate analysis, the variables that were significantly related to the incidence of tooth holes were education ( $\mathrm{p}=$ 0.007 and $\mathrm{OR}=9,692)$, and knowledge $(\mathrm{p}=$ 0.004 and $\mathrm{OR}=11,250$ ). Whereas the nonmean is age $(p=0.667)$. The results of multivariate analysis, the dominant variable associated with the incidence of tooth holes in infants is maternal knowledge $(\mathrm{OR}=$ 9,068).
\end{abstract}


Keywords: Tooth holes, characteristics, and knowledge of the mother

\section{Pendahuluan}

\begin{tabular}{lrr} 
& \multicolumn{2}{r}{ Kesehatan Gigi dan Mulut anak } \\
di $\quad$ Indonesia & masih & sangat \\
memprihatinkan & sehingga & perlu
\end{tabular}
mendapatkan perhatian yang serius dari tenaga kesehatan. Masalah utama yang terjadi dalam rongga mulut adalah karies gigi. Karies gigi adalah penyakit dengan penyebab multifaktor. Prevalensi dan insiden karies gigi dalam suatu populasi dipengaruhi oleh sejumlah faktor resiko seperti jenis kelamin, usia, status sosial ekonomi, pola diet dan kebiasaan menjaga kebersihan gigi dan mulut. Baik gigi sulung maupun gigi permanen, mempunyai resiko terkena karies, namun proses kerusakan gigi sulung lebih cepat menyebar, meluas dan lebih parah dari gigi permanen. Hal tersebut terjadi karena : perbedaan struktur email gigi dimana gigi sulung mempunyai struktur email yang kurang padat dan lebih tipis, morfologi lebih tidak beraturan, dan kontak antara gigi merupakan kontak bidang pada gigi sulung (Suwelo dkk, 1992).

\section{Organisasi Kesehatan Dunia} (WHO) pada tahun 2007 dalam Suciari, dkk (2015) menyatakan bahwa angka kejadian karies gigi pada anak mengalami perlonjakan 60-90\%, sedangkan menurut data dari PDGI (Persatuan Dokter Gigi Indonesia) menyebutkan bahwa sedikitnya $89 \%$ penderita karies adalah anak-anak. Berdasarkan hasil karakteristik survey kesehatan, prevalensi karies gigi pada balita usia 3-5 tahun sebesar 81,7\%. Prevalensi karies gigi menurut kelompok usianya, usia 3 tahun (60\%), usia 4 tahun $(85 \%)$ dan usia 5 tahun $(86,4 \%)$, dengan demikian golongan umur balita merupakan golongan rawan terjadinya karies gigi.

Karies gigi bila tidak dirawat dapat menyebabkan timbulnya rasa sakit bahkan sampai bisa terjadi infeksi. Bila hal tersebut terjadi pada anak-anak, maka dapat menyebabkan gangguan atau kesulitan dalam pengunyahan sehingga asupan gizi berkurang, berat badan menurun dan pada akhirnya tumbuh kembang anak menjadi kurang optimal (Supartinah, 1999).

Peran ibu sangat diperlukan dalam menjaga kesehatan gigi dan mulut anak balita, sebab lingkungan keluarga sangat mendukung tumbuh kembang anak. Peran ibu adalah membimbing, mengingatkan dan memberikan fasilitas terhadap anak agar dapat menjaga kesehatan rongga mulutnya. Orang tua juga berperan penting dalam mencegah akumulasi plak dan terjadinya karies (Yusuf, 2011).

Dukungan pengetahuan yang baik terkait pemeliharaan gigi dan mulut anak menjadi faktor penting yang 
mendasari ibu untuk mencegah anak agar tidak terkena karies gigi. Sebab pengetahuan merupakan salah satu faktor predisposisi dalam pembentukan perilaku pada diri seseorang (Green, 1980).

Posyandu Jeruk terletak di wilayah kelurahan Pondok Labu Jakarta Selatan tepatnya berada di RW 09, posyandu ini belum pernah dilakukan penelitian pengetahuan orang tua tentang cara pemeliharaan kesehatan gigi dan pemeriksaan lubang gigi pada balitanya, para orang tua balita di posyandu jeruk tertarik dan menginginkan dilakukan pemeriksaan gigi geligi terhadap anak balitanya.

Berdasarkan uraian diatas, penulis tertarik untuk melakukan penelitian tentang hubungan karakteristik dan pengetahuan orang tua tentang cara pemeliharaan kesehatan gigi dengan kejadian lubang gigi pada balita di Posyandu Jeruk Kelurahan Pondok Labu tahun 2018.

\section{Metode}

Penelitian ini merupakan penelitian deskriptif dengan desain cross sectional (potong lintang). Penelitian ini dilaksanakan di Posyandu Jeruk Kelurahan Pondok Labu Jakarta Selatan. Waktu penelitian pada bulan April-Mei 2018.
Populasi pada penelitian ini adalah seluruh ibu yang memiliki anak balita dan balita yang berumur 4-5 tahun di Posyandu Jeruk Kelurahan Pondok Labu Jakarta Selatan. Teknik dalam pengambilan sampel ini yaitu porposive sampling dimana sampel diambil berdasarkan pertimbangan tertentu yang dibuat oleh peneliti sendiri. Dalam hal ini sampel berjumlah 47 orang dengan kriteria inklusi sampel adalah:

a. Ibu : mempunyai anak balita yang terdaftar di Posyandu Jeruk Kelurahan Pondok Labu Jakarta Selatan tahun 2018 dan menyetujui serta menandatangani informed consent.

b. Anak balita : Berusia 4-5 tahun Pengumpulan data untuk pengetahuan ibu menggunakan lembar kuesioner dan lembar pemeriksaan lubang gigi susu pada balita di Posyandu Jeruk Kelurahan Pondok Labu Jakarta Selatan tahun 2018. Pengolahan data menggunakan program komputer dan melalui beberapa tahap yaitu editing data, coding data, entry data dan data cleaning. Analisis Data dilakukan secara univariat (distribusi frekuensi), bivariat (uji Kai Kuadrat), dan multivariat (uji Regresi Logistik).

\section{Hasil}

1. Gambaran Kejadian Lubang Gigi

Kejadian lubang gigi diukur berdasarkan banyaknya gigi yang 
mengalami lubang (karies) dari hasil pemeriksaan. Selanjutnya dilakukan pengkategorian berdasarkan nilai tengah (mean/median). Penentuan nilai tengah dilakukan menurut uji kenormalan data dengan menggunakan nilai skewness yang dibagi dengan nilai standar errornya. Pada variabel kejadian lubang gigi, diperoleh nilai skewness yang dibagi dengan nilai standar errornya adalah 4,034, sehingga pengkategorian variabel ini berdasarkan nilai median yaitu 2 . Kategorinya adalah tinggi jika jumlah lubang gigi $\geq 2$ buah gigi, dan rendah jika jumlah lubang gigi $<2$ buah gigi. Secara jelas, hasil jawaban responden dapat dilihat dalam tabel berikut.

Tabel 1

Distribusi Frekuensi Kejadian Lubang Gigi pada Balita di Posyandu Jeruk Kelurahan Pondok Labu Jakarta

Tahun 2018

\begin{tabular}{ccc}
\hline $\begin{array}{c}\text { Kejadian } \\
\text { Lubang Gigi }\end{array}$ & $\begin{array}{c}\text { Frekuensi } \\
(\mathbf{n})\end{array}$ & $\begin{array}{c}\text { Persentase } \\
(\boldsymbol{\%})\end{array}$ \\
\hline Tinggi & 27 & 57,4 \\
\hline Rendah & 20 & 42,6 \\
\hline Total & 47 & 100,0 \\
\hline
\end{tabular}

Berdasarkan tabel 1, diketahui balita yang mengalami lubang gigi kategori tinggi, yaitu sebanyak 27 orang $(57,4 \%)$, sedangkan balita yang lubang giginya kategori rendah, yaitu sebanyak 20 orang $(42,6 \%)$.
2. Gambaran Umur, pendidikan, dan pengetahuan ibu tentang pemeliharaan kesehatan gigi balita

Tabel 2

Distribusi Frekuensi Umur, Pendidikan, dan Pengetahuan Ibu Balita

Di Posyandu Jeruk Kelurahan Pondok Labu Jakarta Tahun 2018

\begin{tabular}{|c|c|c|c|c|}
\hline $\mathbf{N}$ & $\begin{array}{c}\text { Variab } \\
\text { el }\end{array}$ & $\begin{array}{l}\text { Kate } \\
\text { gori }\end{array}$ & $\begin{array}{c}\text { Freku } \\
\text { ensi } \\
\text { (n) }\end{array}$ & $\begin{array}{c}\text { Persen } \\
\text { tase } \\
(\%)\end{array}$ \\
\hline \multirow{2}{*}{1} & \multirow{2}{*}{ Umur } & $\begin{array}{l}<32 \\
\text { tahun }\end{array}$ & 31 & 66,0 \\
\hline & & $\begin{array}{l}\geq 32 \\
\text { tahun }\end{array}$ & 16 & 34,0 \\
\hline \multirow{2}{*}{2} & \multirow{2}{*}{$\begin{array}{l}\text { Pendidi } \\
\text { kan }\end{array}$} & $\begin{array}{c}\text { Rend } \\
\text { ah }\end{array}$ & 16 & 34,0 \\
\hline & & $\begin{array}{l}\text { Tingg } \\
\text { i }\end{array}$ & 31 & 66,0 \\
\hline \multirow{3}{*}{3} & \multirow{2}{*}{$\begin{array}{c}\text { Pengeta } \\
\text { huan }\end{array}$} & $\begin{array}{c}\text { Rend } \\
\text { ah }\end{array}$ & 17 & 36,2 \\
\hline & & $\begin{array}{l}\text { Tingg } \\
\text { i }\end{array}$ & 30 & 63,8 \\
\hline & Total & & 47 & 100,0 \\
\hline
\end{tabular}

Berdasarkan tabel 2, diketahui sebagian besar ibu balita berumur $<32$ tahun, yaitu sebanyak 31 orang $(66,0 \%)$, pendidikan ibu tinggi yaitu sebanyak 30 orang $(66,0 \%)$, dan pengetahuan ibu rendah yaitu sebanyak 20 orang $(62,5 \%)$.

\section{Hasil Analisis Bivariat Umur,} Pendidikan, dan Pengetahuan tentang Pemeliharaan Gigi dengan Kejadian Lubang Gigi

Hasil analisis bivariat antara umur, pendidikan, dan pengetahuan ibu 
dengan kejadian lubang gigi pada balita menggunakan uji Kai Kuadrat, dapat dilihat pada tabel berikut.

Tabel 3

Hasil Analisis Bivariat Hubungan Umur, Pendidikan, dan Pengetahuan Ibu Dengan Kejadian Lubang Gigi Pada Balita Di Posyandu Jeruk Kelurahan Pondok Labu Jakarta Tahun 2018

\begin{tabular}{clccc}
\hline No & Variabel & $\begin{array}{c}p \\
\text { value }\end{array}$ & OR & Kesimpulan \\
\hline 1 & $\begin{array}{l}\text { Hubungan } \\
\text { Umur ibu } \\
\text { Dengan } \\
\text { kejadian } \\
\text { lubang gigi } \\
\text { pada balita }\end{array}$ & 0,667 & 1,583 & $\begin{array}{c}\text { Tidak ada } \\
\text { hubungan } \\
\text { bermakna }\end{array}$ \\
\hline 2 & $\begin{array}{l}\text { Hubungan } \\
\text { pendidikan } \\
\text { ibu dengan } \\
\text { kejadian } \\
\text { lubang gigi } \\
\text { pada balita }\end{array}$ & 0,007 & 9,692 & $\begin{array}{c}\text { Ada } \\
\text { hubungan } \\
\text { bermakna }\end{array}$ \\
\hline 3 & $\begin{array}{l}\text { Hubungan } \\
\text { pengetahuan } \\
\text { ibu dengan } \\
\text { kejadian } \\
\text { lubang gigi } \\
\text { pada balita }\end{array}$ & 0,004 & 11,250 & $\begin{array}{c}\text { Ada } \\
\text { hubungan } \\
\text { bermakna }\end{array}$ \\
\hline
\end{tabular}

Berdasarkan tabel 2, diketahui variabel yang memiliki hubungan bermakna dengan kejadian lubang gigi adalah pendidikan ibu $(\mathrm{p}=0,007$ dan $\mathrm{OR}$ =9,692), dan pengetahuan ibu ( $\mathrm{p}=0,004$ dan $\mathrm{OR}=11,350)$. Sedangkan yang tidak berhubungan secara bermakna dengan kejadian lubang gigi adalah variabel umur ibu $(\mathrm{p}=0,667)$.

\section{Hasil Analisis Multivariat}

Hasil akhir analisis multivariat hubungan ketiga variabel independen (umur, pendidikan, dan pengetahuan) diperoleh hasil bahwa umur ibu keluar dari pemodelan multivariat karena memiliki nilai $\mathrm{p}>0,05$ $(0,541)$, sehingga hanya tersisa 2 variabel independen, yaitu pendidikan dan pengetahuan ibu. Hasil akhir analisis multivariat dapat dilihat dalam tabel berikut :

Tabel 4

Hasil Akhir Analisis Regresi Logistik Antara Variabel Umur, Pendidikan dan Pengetahuan Ibu

\begin{tabular}{lcccc}
\hline Variabel & B & P & OR & R2 \\
\hline Pendidikan & 2,032 & 0,023 & 7,630 & $42,1 \%$ \\
\hline Pengetahuan & 2,205 & 0,013 & 9,068 & \\
\hline
\end{tabular}

Hasil analisis diatas, ternyata ada 2 variabel mempunyai nilai $\mathrm{p}<0,05$, yaitu pendidikan dan pengetahuan ibu, sehingga dapat disimpulkan variabel pendidikan dan pengetahuan ibu berhubungan secara signifikan dengan kejadian lubang gigi pada balita.

Dan dari variabel tersebut, faktor dominan paling tinggi adalah 
pengetahuan $(\mathrm{OR}=9,068)$

berhubungan dengan kejadian lubang gigi pada balita, artinya ibu yang pengetahuannya tinggi akan berpeluang 9 kali balitanya tidak mengalami lubang gigi kategori tinggi dibandingkan dengan ibu yang pengetahuannya rendah setelah dikontrol variabel pendidikan ibu dengan kontribusi sebesar $42,1 \%$.

\section{Pembahasan}

\section{Kejadian Lubang Gigi}

Kejadian lubang gigi diukur berdasarkan banyaknya gigi yang berlubang dari hasil pemeriksaan. Dari hasil penelitian, diketahui balita yang mengalami lubang gigi kategori tinggi, yaitu sebanyak 27 orang $(57,4 \%)$, sedangkan balita yang lubang giginya kategori rendah, yaitu sebanyak 20 orang $(42,6 \%)$.

Lubang gigi merupakan suatu penyakit jaringan keras gigi, yaitu email, dentin, dan sementeum, yang disebabkan oleh aktifitas suatu jasad renik dalam suatu karbohidrat yang dapat diragikan. Tandanya adalah demineralisasi jaringan keras gigi yang kemudian diikuti oleh kerusakan bahan organiknya. Akibatnya, terjadi invasi bakteri dan kematian pulpa serta penyebaran infeksinya ke jaringan periapeks yang dapat menyebabkan rasa nyeri (Kidd, 1992).

Dalam penelitian ini sebanyak $57,4 \%$ balita telah mengalami gigi berlubang kategori tinggi (> 2 buah). Hal tersebut dapat terjadi karena berbagai faktor, seperti halnya kebiasaan mengkonsumsi makanan manis (kariogenik), perawatan gigi yang kurang, dan sebagainya.

\section{Umur Ibu}

Berdasarkan hasil penelitian, diketahui sebagian besar ibu balita berumur < 32 tahun, yaitu sebanyak 31 orang $(66,0 \%)$. Hasil analisis bivariat membuktikan tidak adanya hubungan bermakna antara umur ibu dengan kejadian lubang gigi pada balita $(\mathrm{p}=0,667)$.

Menurut Mubarak et al (dalam Cahyono, 2010), dengan bertambahnya umur seseorang akan mengalami perubahan aspek fisik dan psikologis (mental). Secara garis besar, pertumbuhan fisik terdiri atas empat kategori perubahan yaitu perubahan ukuran, perubahan proposi, hilangnya ciriciri lama dan timbulnya ciri-ciri baru. Perubahan ini terjadi karena pematangan fungsi organ. Pada aspek psikologis atau mental, taraf berpikir seseorang menjadi semakin matang dan dewasa. 
Dalam penelitian ini, ternyata umur ibu tidak berpengaruh terhadap kejadian lubang gigi pada balita. Hal tersebut terjadi karena adanya faktor lain yang lebih dominan pengaruhnya, seperti halnya pengetahuan ibu dan pendidikan ibu.

Ibu yang umurnya relatif muda $(<32$ tahun) namun apabila pendidikannya tinggi dan atau pengetahuan tentang pemeliharaan giginya baik, maka otomatis akan berpengaruh terhadap tindakannya dalam menjaga kesehatan gigi dan mulut balitanya, sehingga kondisi ini akan menurunkan risiko terjadinya lubang gigi pada balitanya.

\section{Pendidikan Ibu}

\section{Berdasarkan}

hasil penelitian, diketahui sebagian besar pendidikan ibu adalah tinggi yaitu sebanyak 66,0\%. Hasil analisis bivariat membuktikan adanya hubungan bermakna antara pendidikan ibu dengan kejadian lubang gigi pada balita $(\mathrm{p}=0,007$ dan $\mathrm{OR}=9,692$ ).

Menurut Mubarak et al (dalam Cahyono, 2010) faktorfaktor yang mempengaruhi pengetahuan seseorang salah satunya adalah pendidikan. Pendidikan berarti bimbingan yang diberikan seseorang kepada orang lain agar dapat memahami sesuatu hal, tidak dapat dipungkiri bahwa semakin tinggi pendidikan seseorang maka semakin mudah pula mereka menerima informasi dan pada akhirnya pengetahuan yang di milikinya akan semakin banyak. Sebaliknya, seseorang memiliki tingkatan pendidikan rendah maka akan menghambat perkembangan sikap orang tersebut terhadap penerimaan informasi dan nilai-nilai yang baru diperkenalkan.

Semakin tinggi tingkat pendidikan ibu, maka peluang untuk memiliki wawasan luas akan lebih baik dibandingkan dengan ibu yang berpendidikan rendah, sehingga kondisi ini dapat mempengaruhi tindakan ibu dalam menjaga kesehatan gigi balitanya, dan pada akhirnya berdampak pula pada status kesehatan gigi dan mulut anaknya.

\section{Pengetahuan Ibu}

Berdasarkan hasil penelitian, diketahui sebagian besar pengetahuan ibu adalah rendah yaitu sebanyak 20 orang $(62,5 \%)$. Hasil analisis bivariat membuktikan adanya hubungan bermakna antara pengetahuan ibu dengan kejadian lubang gigi pada balita $(\mathrm{p}=0,004$ dan $\mathrm{OR}=11,350)$. 
Pengetahuan adalah hasil dari tahu dan terjadi setelah orang melakukan pengindraan terhadap suatu objek tertentu, pengindraan terjadi melalui panca indra manusia, yakni indera penglihatan, pendengaran, penciuman, rasa dan raba. Sebagin besar pengetahuan manusia diperoleh dari mata dan telinga. (Notoatmodjo, 2012).

Banyak faktor $\begin{array}{r}\text { yang } \\ \text { sulitnya } \\ \text { menyebabkan } \\ \text { meningkatkan status kesehatan gigi }\end{array}$
dan mulut anak di Indonesia. Tapi
mungkin perlu dicermati satu hal
yang teramat penting, yaitu peranan
ibu. Ibu memegang peranan penting
dalam keluarga, sebagai seorang
istri dan ibu dari anak-anaknya.

Kadang anak yang masih berusia di bawah 5 tahun sangat sulit untuk disuruh menyikat gigi. Di sinilah letak peran ibu. Sekedar perintah mungkin tidak mempan untuk membuat anak mau menyikat gigi. Tapi kalau ibu mengajak si anak bersama-sama menyikat gigi, saat mandi misalnya, maka anak dapat memperhatikan dan mencontoh kebiasaan ibu (Ngatemi, 2013).

Penelitian Rahmandhini, dkk (2017) juga mengemukakan bahwa dari hasil tabulasi silang menunjukan tingkat pengetahuan ibu tentang makanan kariogenik sebagian besar $(45,5 \%)$ termasuk pada kategori baik dengan jumlah karies gigi sebagian besar siswa termasuk dalam kategori sedikit. Artinya semakin baik pengetahuan ibu maka kemungkinan kejadian karies gigi pada balita juga lebih kecil.

\section{Faktor Dominan Yang} Mempengaruhi Kejadian Lubang Gigi Balita

Hasil analisis multivariat membuktikan, faktor dominan paling tinggi adalah pengetahuan $(\mathrm{OR}=9,068)$ berhubungan dengan kejadian lubang gigi pada balita, artinya ibu yang pengetahuannya tinggi akan berpeluang 9 kali balitanya tidak mengalami lubang gigi kategori tinggi dibandingkan dengan ibu yang pengetahuannya rendah setelah dikontrol variabel pendidikan ibu dengan kontribusi sebesar $42,1 \%$.

Pengetahuan merupakan salah satu faktor predisposisi dalam pembentukan perilaku pada diri seseorang (Green, 1980). Figur pertama yang dikenal anak begitu ia lahir adalah ibunya. Maka dari itu, perilaku dan kebiasaan ibu dapat dicontoh oleh sang anak. Pengetahuan ibu tentang kesehatan 
gigi akan sangat menentukan status kesehatan gigi anaknya kelak. Namun 'tahu' saja tidak cukup, perlu diikuti dengan 'peduli' dan 'bertindak (Ngatemi, 2013).

Hasil penelitian Pamunarsih (2008) menunjukkan ada hubungan yang bermakna antara pengetahuan, sikap dan praktik ibu dengan status kesehatan gigi dan mulut anak usia prasekolah.

\section{Kesimpulan}

1. Dari hasil penelitian, diketahui balita yang mengalami lubang gigi kategori tinggi, yaitu sebanyak 57,4\%, sebagian besar ibu balita berumur $<32$ tahun (66,0\%), pendidikan ibu adalah tinggi $(660,3 \%), \quad$ dan pengetahuan ibu sebagian besar dalam kategori tinggi $(63,8 \%)$.

2. Hasil analisis bivariat, variabel yang membuktikan adanya hubungan bermakna dengan kejadian lubang gigi pada balita adalah pendidikan ibu $(\mathrm{p}=0,007$ dan $\mathrm{OR}=9,692)$ dan pengetahuan ibu $(\mathrm{p}=0,004$ dan $\mathrm{OR}=11,350)$. Sedangkan variabel yang membuktikan tidak adanya hubungan bermakna dengan kejadian lubang gigi pada balita adalah umur ibu $(p=0,667)$.

\section{Daftar Pustaka}

Cahyono, Indro Eko, 2010 Hubungan dan motivasi ibu terhadap perawatan gigi anak usia 1-3 tahun di Desa Balesno Kecamatan Nganut Kabupaten Tulunggung.

Djamil, Melanie S, 2011. A-Z Kesehatan gigi (panduan lengkap kesehatan gigi keluarga), Metagraf. Solo

Ghofur, Abdul, 2012. Belajar pintar kesehatan gigi dan mulut. Mitra buku: Yogyakarta

Kementerian Kesehatan.2013. Peraturan menteri kesehatan RI Nomor 25 tahun 2013 tentang upaya kesehatan gigi anak

Kementerian Kesehatan.2013 Riskesdas 2013 badan penelitian dan pengembangan kesehatan kementerian kesehatan RI.

Kidd, Edwina A.M, 2002. Dasar-dasar karies penyakit dan penanggulangannya. EGC: Jakarta

Ngatemi, 2013. Hubungan Faktor Manajemen Pelaksanaan UKGS Dan Peran Orangtua Terhadap Status Kesehatan Gigi Dan Mulut Murid Sekolah Dasar Binaan Di Wilayah Kerja Puskesmas Kecamatan Cilandak Jakarta Selatan Tahun 2011. Dalam Tesis UHAMKA.

Notoatmodjo, Soekidjo, 2007. Promosi Kesehatan dan ilmu perilaku. Rineka cipta: Jakarta

Rahmandhini, dkk, 2017. Gambaran Pengetahuan Dan Sikap Ibu Tentang Makanan Kariogenik Dengan Jumlah Karies Gigi Pada Siswa Kelas IV SD Negeri Demakijo 1. Jurnal Gigi Dan Mulut Vol.4, NO. 1, April 2017

Suwelo. 1992. Karies Gigi pada Anak dengan Pelbagai Faktor Etiologi: Kajian pada Anak Usia Prasekolah. EGC: Jakarta

Yusuf, M. 2011. Hubungan Pengetahuan Kesehatan Gigi Dan Mulut Dengan Status Karies Dan Ohis Pada Anak SMP. Medan: FKG USU. Hal: 6

http://www.depkes.go.id di akses pada tanggal 16 Maret 2018 
14 Quality Jurnal Kesehatan Vol. 9 No. 1, November 2018, Hal. 1-41 